\title{
The Centrifugal Modeling of Reinforcement on Approaches to Railway Bridges
}

\author{
Ahmad Alkhdour'1 , Oleksii Tiutkin², Vitalii Marochka², \\ Stepan Boboshko ${ }^{2}$
}

${ }^{1}$ Department of Civil Engineering, Al-Balqa Applied University, Al-Salt, 19117, Jordan, a.alkhdour@bau.edu.jo

${ }^{2}$ Department of Transport Infrastructure, Dnipro National University of Railway Transport named after Academician V. Lazaryan, Lazaryan Str., 2, Dnipro, 49010, Ukraine, \{tiutkin, vitalij_marochka, stepan_boboshko\}@diit.edu.ua

\begin{abstract}
The purpose of the research is to test models of sections with transient stiffness on approaches to railway bridges in the laboratory. The feasibility of the proposed methods of reinforcing the transient stiffness areas to ensure normal operation and avoid the formation of significant deformations had been tested. Centrifugal simulation of three types of reinforcement of transition section had been performed. The deformations of the models of the section with transient stiffness on approach to the railway bridge had been obtained. A comparative analysis of the results of centrifugal experiments had been performed. The effectiveness of each of the reinforcement options had been determined and the most rational method of reinforcement had been concluded.
\end{abstract}

Keywords: centrifugal modeling; reinforcement; railway bridge

\section{Introduction}

The problem of the normal operation of sections with transient stiffness on approaches to railway bridges is that the dynamic impact of rolling stock adversely affects the embankment. Changing the significant rigidity of the bridge elements, that is, the abutment and superstructure, to a lesser rigidity of the embankment causes its considerable, and sometimes excessive, deformation. This requires measures that impair the operation: reducing the speed of movement, repairing, redeveloping or reconstructing the embankment.

This problem was engaged in very fruitful in 1990-2020, but the proposed solutions (geogrid reinforcement [1-2], ballast material [3-5], bitumen emulsion [6], soil cement piles [7], variable stiffness [8, 9], boring and mixing technology [10]) were not always rational. This is due to the fact that the sections with 
transient stiffness on approaches to the railway bridges were not thoroughly investigated. There are several research methods, the main ones being mathematical modeling, experimental research, and field tests [10, 11]. Because full-scale bridge testing requires a large amount of time and financial cost to implement, experimental modeling becoming increasingly popular [10-12]. One of the methods of experimental modeling based on physical device - centrifuge [12]. It is this method of research that gives knowledge of the general nature of deformation, which is of great importance for the correct formulation of theoretical studies and for the explanation of certain phenomena occurring in nature.

The essence of the centrifugal simulation method is that the field of centrifugal forces created by the rotation of the centrifugal machine is used as a force field similar to gravity [12]. A model of a soil structure made of natural material is placed in a centrifuge, creating a rotating field of centrifugal forces similar to gravity, which has a much higher intensity. Thus, centrifugal modeling ensures the complete preservation of the nature of processes occurring in the structure.

It is worth noting that the similarity conditions that apply to models with the location of individual simulation regions at different distances from the center of rotation are practically unworkable, since it is impossible to ensure the rotation of these simulation regions at different angular velocities. For correct centrifugal simulation experiments, the same starting conditions for each iteration must be carefully observed. As a result, minimal changes to starting conditions can lead to incorrect results.

\section{Methods and Resources}

The experimental model was based on a real railway bridge on the Loshkarovka Pavlopillya section of the Merefa - Kherson line in Ukraine. An experimental model with a total length of $32.5 \mathrm{~m}$ covers the abutment construction and the approach area $20 \mathrm{~m}$ behind it.

The tests had been performed at a unique centrifuge of the Soil Mechanics Research Laboratory of Dnipro National University of Railway Transport (DNURT) named after Academician V. Lazaryan. The DNURT machine is one of the most powerful centrifugal devices used in the world. Thus, with a large mass of test models $(2 \times 120 \mathrm{~kg})$ and an effective rotation radius of $2.28 \mathrm{~m}$, the device is able to develop any speed within the range from 0 to $250 \mathrm{rpm}$. The total acceleration is from $1 \mathrm{~g}$ to $160 \mathrm{~g}$.

The kinematic scheme of the centrifugal machine is constructed in such a way that the torque from the traction motor through the gear reducer is transmitted to the vertical shaft of the machine, with which the two-shoulder yoke rotates, at the 
ends of which are pivotally suspended carriages. As the machine is overclocked, the carriages are rotated and mounted horizontally (Figure 1).

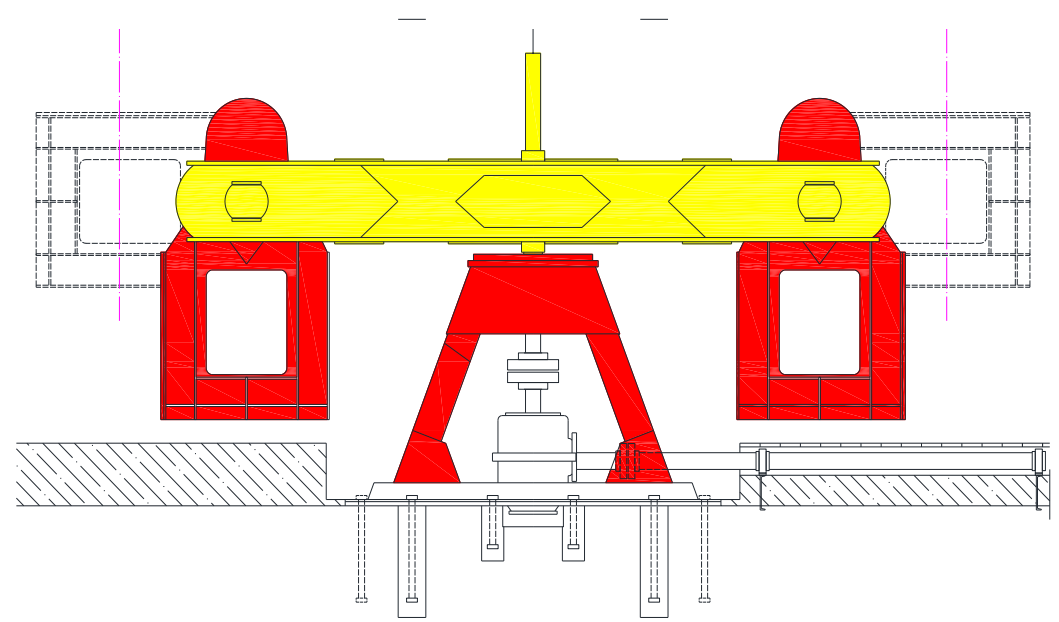

Figure 1

The design of the centrifuge

The model of the investigated structure, which is in the carriage, is the total attachment root of the centrifugal force and gravity that is, the process of modeling. The tray, which is made for modeling, made of metal, one of the walls can be removed. The internal dimensions of the tray are $650 \times 235 \times 360 \mathrm{~mm}$. The abutment model (Figure 2) is mounted in a test tray on a soil cushion $2 \ldots 3$ cm thick.

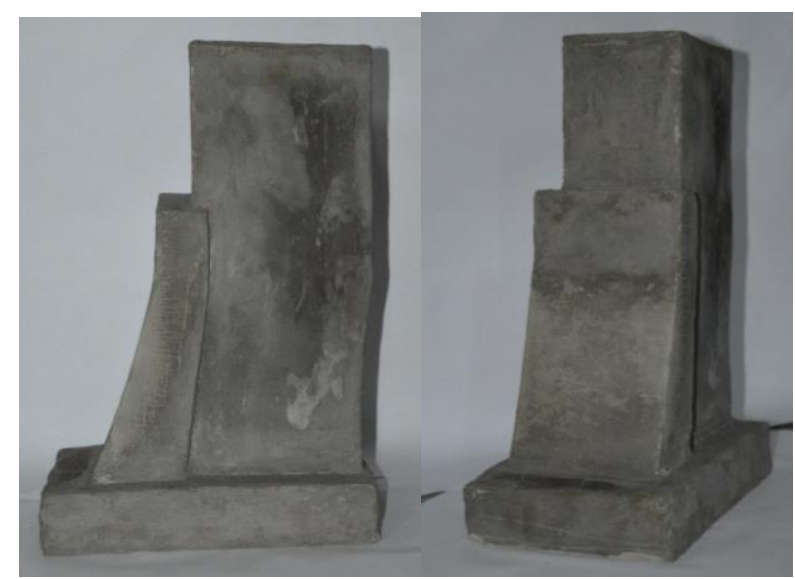

Figure 2

The model of the abutment of the bridge made of cement 
The soil is compacted by manual ramming to the specified density. The model is covered with layers of soil $4 \ldots 5 \mathrm{~cm}$, which are further compacted in accordance with the first layer to model the embankment as a solid array. The lateral topsoil of the soil array had been divided by a pencil grid (Figure 3 ) into $2 \times 2 \mathrm{~cm}$ squares for better inspection and processing of test results.

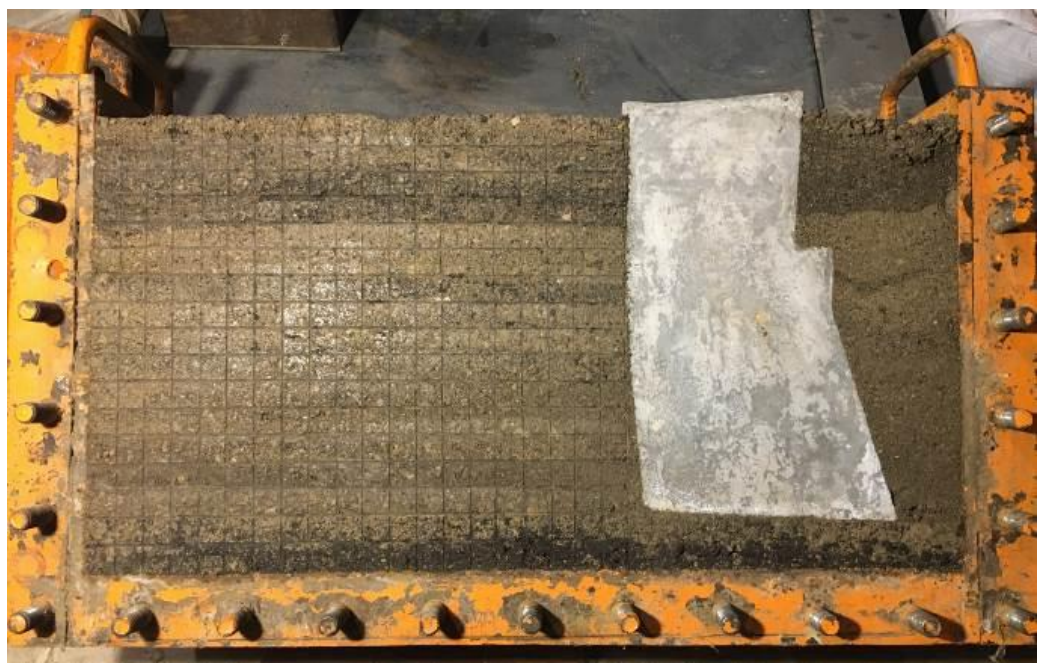

Figure 3

Model appearance in the centrifuge cassette

The resulting soil mass is given an embankment shape by cutting slopes according to the real bridge.

The physical and mechanical characteristics of the soil of the base are as follows: clay of dark brown color of plastic consistency with index of fluidity $I_{L}=0.7$, plasticity index $I_{P}=0.23$, the density of the soil when making the model $\rho=1.884$ $\ldots 1.911 \mathrm{~g} / \mathrm{cm}^{3}$, dry soil density $\rho_{c}=1.299 \ldots 1.317 \mathrm{~g} / \mathrm{cm}^{3}$, humidity $W=0.40 \ldots$ 0.41 , porosity coefficient $e=1.106 \ldots 1.135$, the degree of humidity $S_{r}=0.94$.

The tray had been mounted in a centrifuge. To counterbalance on the other side of the centrifuge lever had been set counter. Centrifugal acceleration equal to the inverse of the scale of the model, i.e. $50 \mathrm{~g}$ had been given to simulate the loading on the soil of the bulkhead of the centrifuge. Acceleration of the centrifugal machine in all experiments had been carried out uniformly with the increase of scale of simulation for $5 \mathrm{~min}$ and corresponded to time in kind 24 months.

After stopping the centrifuge, a visual description of the condition of the model, removal of deformation of the mesh and photographing had been performed. After completing the program and checking the model, it had been found that the model was built without significant deviations. The marked grid made it possible to outline the intensity of the load distribution on the soil of the embankment. 


\section{Output Data of the Experiment}

Weight of the container with model No. 1: $194.5 \mathrm{~kg}$; weight of the container of counterweight No. 1: $194.5 \mathrm{~kg}$.

Weight of the container with model No. 2: $205.0 \mathrm{~kg}$; weight of the container with counterweight No. $2: 205.0 \mathrm{~kg}$.

Weight of container with model No. 3: $200.0 \mathrm{~kg}$; weight of the container counterweight No. 3: $200.0 \mathrm{~kg}$.

Weight of container with model No. 4: $201.5 \mathrm{~kg}$; weight of the container of counterweight No. $4: 201.5 \mathrm{~kg}$.

Modeling Scale: 1: 10000 (1 hour equals 10.000 hours); rotation time: 60 minutes (equal to 416 days); central gearbox conversion factor: 1.576; (1 turn of the centrifuge $=1.576$ engine turns). This is an equation example:

$a_{c}=\omega^{2} R$,

$\omega=2 \pi f$,

where " $f$ " is the speed of centrifuge (desired value):

$a_{c}=(2 \pi)^{2} f^{2} R$,

$f^{2}=\frac{a_{c}}{4 \pi^{2} R}$

$f=\sqrt{\frac{a_{c}}{4 \pi^{2} R}}$,

where " $R$ " is the effective radius of the centrifuge $R=2.28 \mathrm{~m} ; a_{c}$ - centrifugal acceleration $\left(a_{c}=50 \mathrm{~g}\right)$;

$f=\sqrt{\frac{50 \cdot 9.81}{4 \pi^{2} \cdot 2.28}}=2.334 \mathrm{~Hz}$.

Engine speed:

$n_{o}=f \cdot 1.576=2.334 \cdot 1.576=220.74 \mathrm{rpm}$, or

$n_{o}=\frac{60 f_{c}}{4}$.

Frequency of current:

$f_{c}=\frac{4 n_{o}}{60}=\frac{4 \cdot 220.74}{60}=14.72 \mathrm{~Hz}$. 


\section{Results}

Three types of reinforcement of the embankment consignment had been selected for verification and comparison: 1) reinforcement by gabion boxes; 2) reinforcement by vertical soil cement piles; 3) the use of reinforced and sorted soils.

The reinforcement of the gabion boxes was as follows. As in the non-reinforced ones, the abutment model is mounted on a dense, cushioned pillow, after which layers of $4 \ldots 5 \mathrm{~cm}$ had been rammed to form the main soil mass. During backfilling and ramming of the upper layers, part of the backfill soil is replaced by models of gabion boxes of three sizes: $3000 \times 2500 \times 1500 \mathrm{~mm}, 3000 \times 2500 \times 1200$ $\mathrm{mm}$ and $3000 \times 2500 \times 900 \mathrm{~mm}$ (Figure 4).

a)

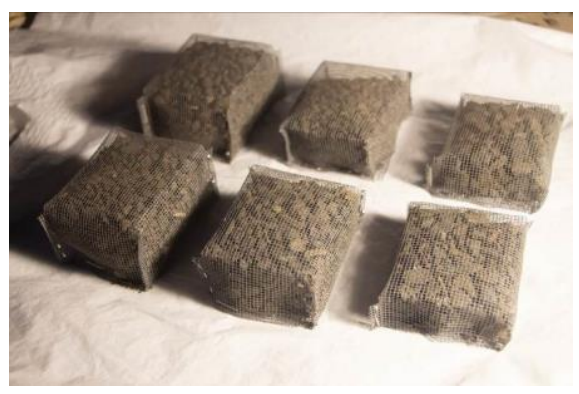

b)
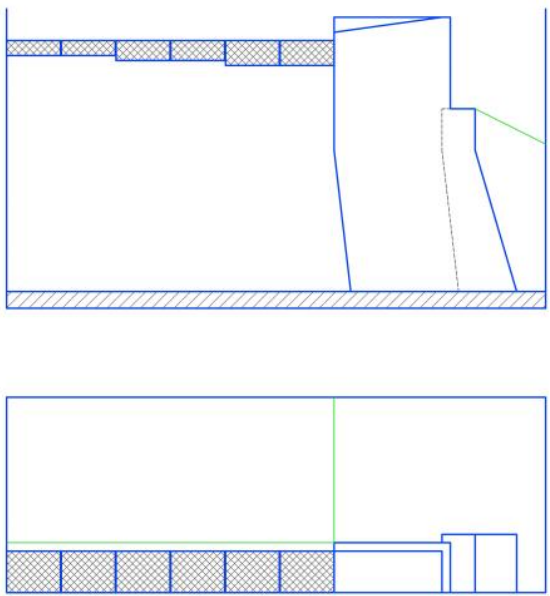

Figure 4

a) The appearance of models of gabion boxes;

b) their arrangement scheme in the centrifuge cassette 
Polymer mesh and crushed stone of fraction $3 \ldots 5 \mathrm{~mm}$ had been used for modeling of gabions. The resulting soil mass is provided with an embankment shape by cutting slopes according to a real bridge (Figure 5).

a)

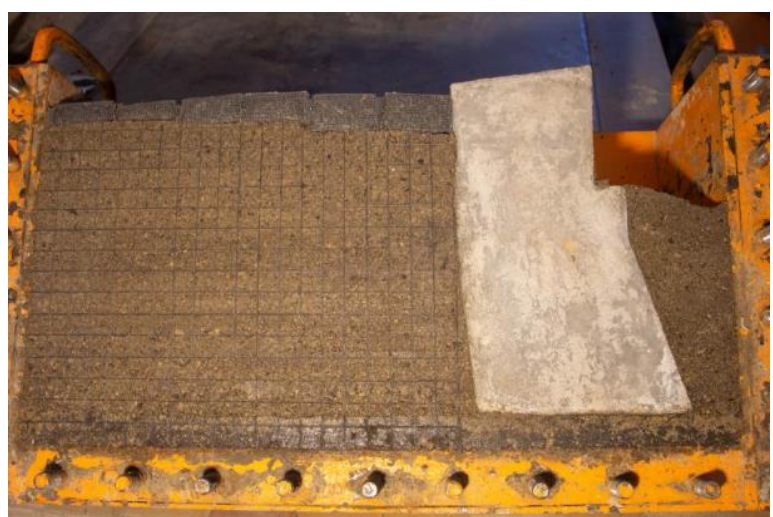

b)

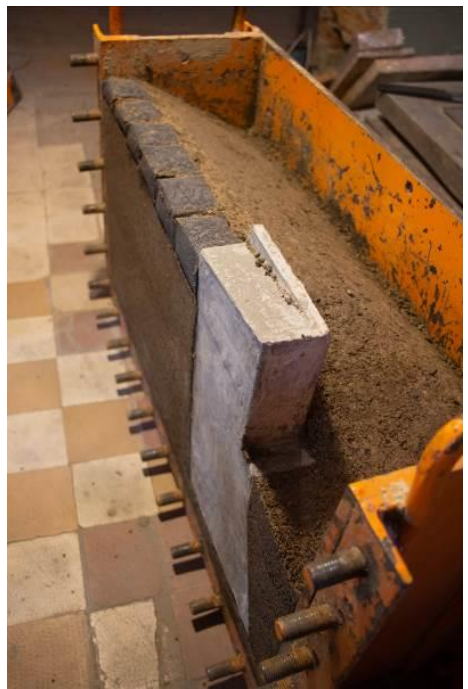

Figure 5

View of model with gain gabion boxes: a) in plan; b) in top

After stopping the centrifuge, a visual description of the model's condition, mesh deformation, and photographing had been performed.

Reinforcement with soil cement piles has several advantages over the earlier method. First of all, it is an opportunity to strengthen the existing railway bridge embankments without dismantling the upper structure of the track, which not only 
reduces the labor costs for the reinforcement works, but also reduces the rail losses from closing the line for the period of repair. The reinforcement is performed by paired soil cement piles with a diameter of $30 \mathrm{~cm}$ of various lengths with a step of $1 \mathrm{~m}$ between them along and across the bridge. Reinforcement begins at a distance of $2 \mathrm{~m}$ from the abutment structure to ensure the safety.

The reinforcement model is as follows: as in the non-reinforcement test, the abutment model is mounted on a tightly packed pillow, after which layers of $4 \ldots$ $5 \mathrm{~cm}$ are formed and the main soil mass is formed by the ram. After giving the array an embankment shape, vertical holes of the design length are drilled in the upper part of the embankment, which are tightly filled with soil cement solution (Figure 6).

a)

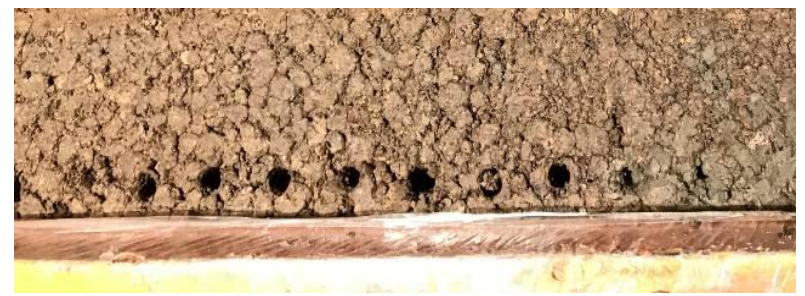

b)
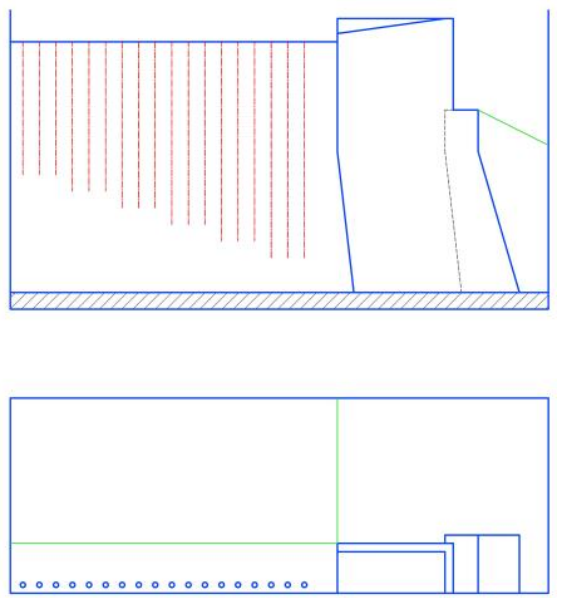

Figure 6

a) The appearance of model with soil cement piles;

b) Their arrangement scheme in the centrifuge cassette

Reinforcement with the help of sorted soils is performed by stabilizing part of the embankment $2.5 \ldots 3 \%$ of cement, using sorted soil and performing a horizontal pillow of tightly compressed soil (Figure 7) [13]. 


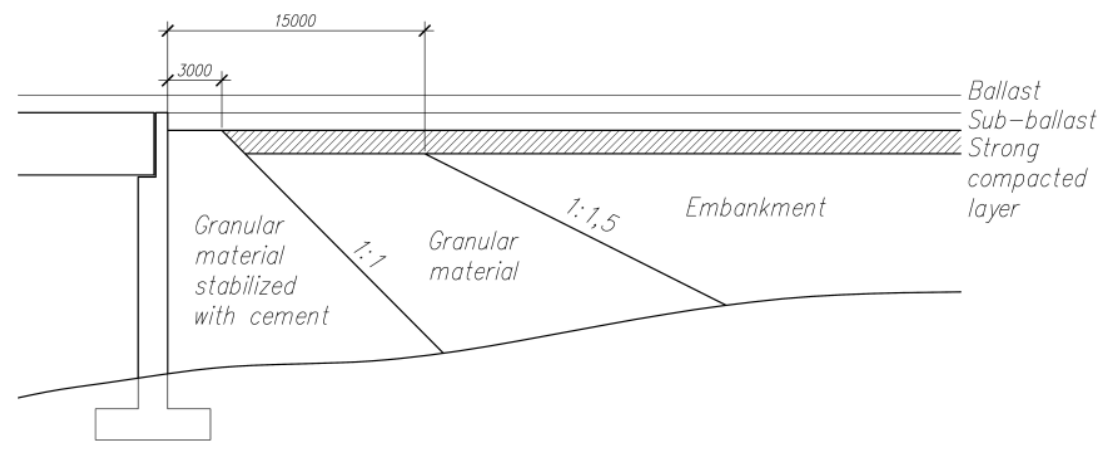

Figure 7

Reinforcement of the transitional area by sorted soils (drawing taken from work [13])

In contrast to the non-reinforcement test, one part of the layer of rammed soil is cement-stabilized soil, the second is sorted soil, and the other is ordinary soil (Figure 8).

a)

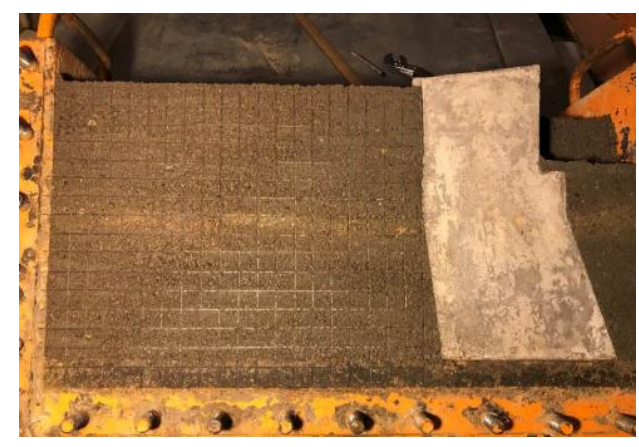

b)

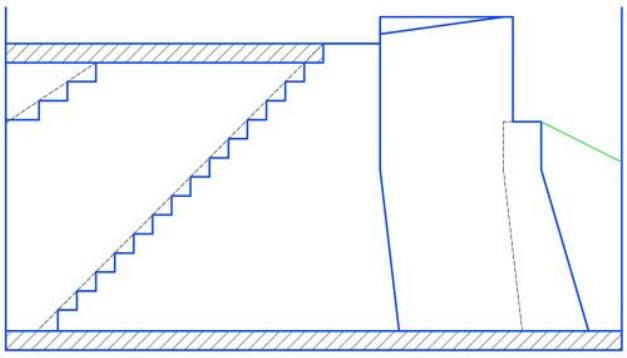

Figure 8

a) The appearance of model with sorted soil;

b) their arrangement scheme in the centrifuge cassette 
After stopping the centrifuge, a visual description of the condition of the model, deformation of the grid and photographing had been carried out. In Figures 9-11 models of three variants of reinforcement after deformation in a centrifuge are presented.

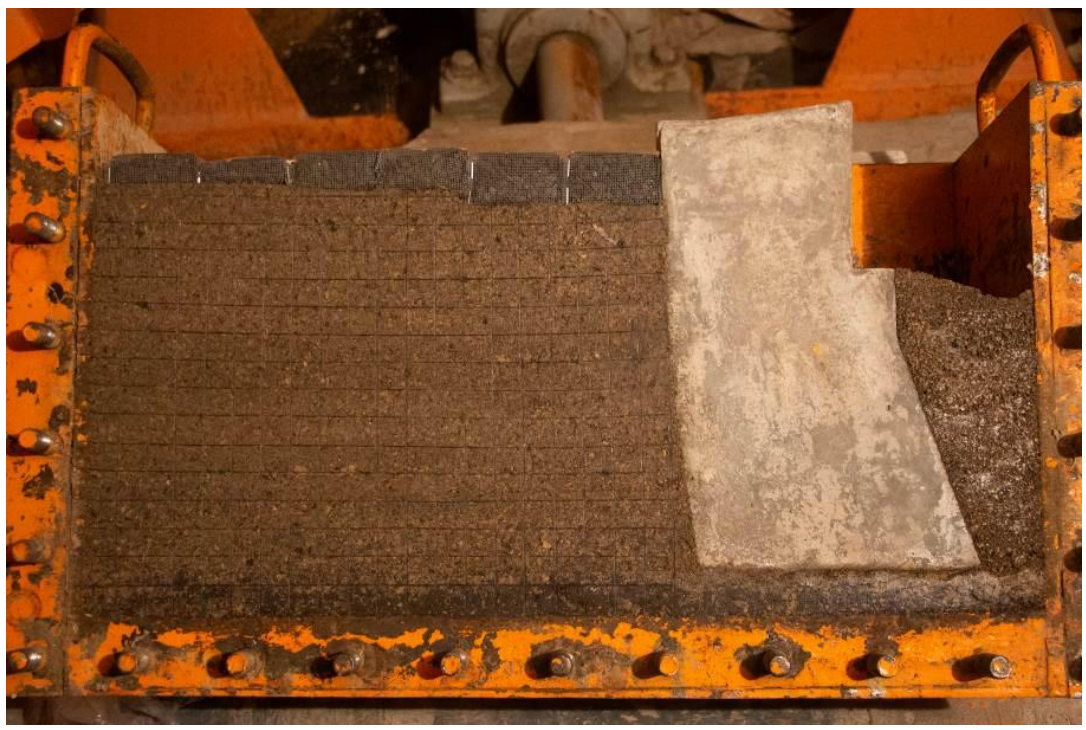

Figure 9

Deformed bridge and embankment models with reinforced gabion boxes

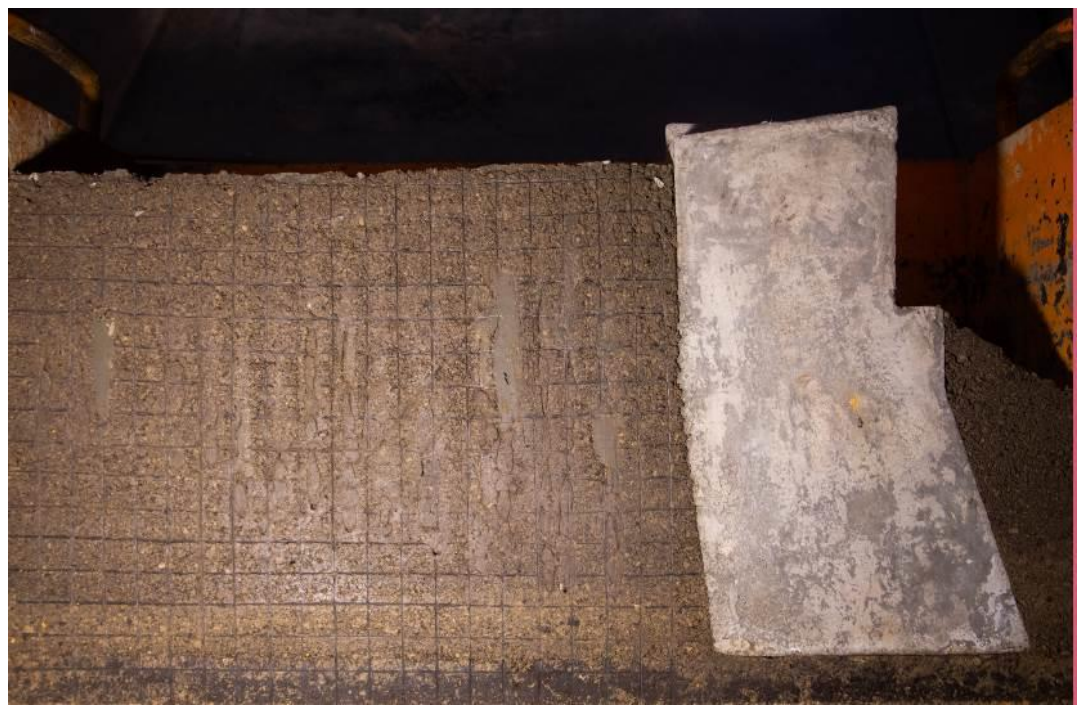

Figure 10

Deformed bridge and embankment models with reinforced soil cement piles 


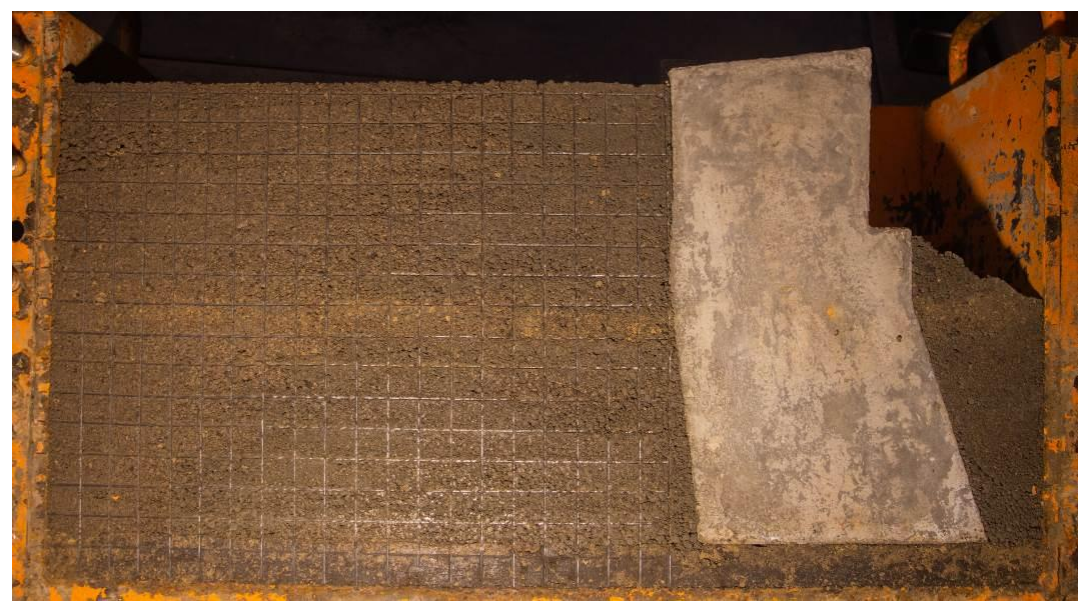

Figure 11

Deformed bridge and embankment models with reinforced sorted soil

After processing the results, the original photos and the results of each test had been converted to a digital vector view and overlaid for comparison. The comparison showed the following results of maximum vertical deformation: for the test without reinforcement $-20.56 \mathrm{~mm}$; for the test with reinforcement gabion boxes $-5.46 \mathrm{~mm}$; $9.77 \mathrm{~mm}$ for soil reinforcement piles; $5.33 \mathrm{~mm}$ for graded soil reinforcement test.

\section{Conclusions}

Thus, studies conducted using centrifugal modeling of reinforced sections with transient stiffness on approaches to railway bridges allow comparative analysis. It testifies that the use of all three variants of reinforcement (gabion boxes, soil cement piles and sorted soil) has a positive effect on the reduction of vertical deformations $(2.10 \ldots 3.86$ times $)$. It is also possible to conclude that two of the three variants of reinforcement are almost equal from the point of view of reduction of vertical deformations: reinforcement by gabion boxes -3.77 times, reinforcement by sorted soil -3.86 times. The option of reinforcing soil cement piles, which is effective in other cases, in a particular reinforcement of sections with transient stiffness on approaches to railway bridges is less effective. Further research, which will compare the technologies of gabion-box reinforcement and sorted soil, will prove the most rational technology in terms of financial and labor costs.

\section{References}

[1] Sz. Fischer, F. Horvát. Investigation of the reinforcement and stabilisation effect of geogrid layers under railway ballast. Slovak Journal of Civil Engineering, Vol. XIX, 3, 2011, pp. 22-30 
[2] E. Juhasz, S. Fischer. Investigation of railroad ballast particle breakage. Pollack Periodica, Vol. 14(2), 2019, pp. 3-14

[3] D. Bannikov, A. Radkevich. Analytical method for compiling and applying a ballast map for the traction unit Pe2U. Eastern-European Journal of Enterprise Technologies, Vol. 2(1-98), 2019, pp. 6-14

[4] M. Sysyn, V. Kovalchuk, U. Gerber, O. Nabochenko, A. Pentsak. Experimental study of railway ballast consolidation inhomogeneity under vibration loading. Pollack Periodica, Vol. 15(1), 2020, pp. 27-36

[5] M. Amine Benmebarek, M. M. Rad. Dem modeling of crushable grain material under different loading conditions. Periodica Polytechnica Civil Engineering, Vol. 65(3), 2021, pp. 935-945

[6] M. Iwański, A. Chomicz-Kowalska. Application of the foamed bitumen and bitumen emulsion to the road base mixes in the deep cold recycling technology. Baltic Journal of Road and Bridge Engineering, Vol. 11(4), 2016, pp. 291-301

[7] O. Dubinchyk, V. Petrenko, D. Ihnatenko, V. Kildieiev. Comprehensive analysis of the retaining pile structure with the determining the stability factor by numerical methods, International Conference Essays of mining science and practice, E3S Web of Conferences 109, 00020, 2019

[8] D. Kurhan, M. Kurhan, M. Husak. Impact of the variable stiffness section on the conditions of track and rolling stock interaction. IOP Conference Series: Materials Science and Engineering, Vol. 985, 2020, 012005

[9] D. Kurhan, M. Kurhan. Modeling the Dynamic Response of Railway Track. IOP Conf. Ser.: Materials Science and Engineering. Vol. 708, 2019, 012013

[10] O. L. Tiutkin, L. Neduzha, J. Kalivoda. Finite-element Analysis of Strengthening the Subgrade on the Basis of Boring and Mixing Technology. Transport Problems, 16(2), 2021, pp. 1-10

[11] J. E. Nicks. The bump at the end of the railway bridge. Doctoral dissertation, 2009, Texas A\&M University

[12] D. Ignatenko, O. L. Tiutkin, V. D. Petrenko, A. M. Alkhdour. Application of centrifugal modeling for the study of landscape structure stability. International Journal of Civil Engineering and Technology, Vol. 10(01), 2019, pp. 2179-2187

[13] V. V. Marochka, S. H. Boboshko. Analysis of the problems of sections with the transitional rigidity indicator in world bridging. Bridges and tunnels: Theory, Research, Practice, 16, 2019, pp. 82-92 